\title{
40-Year Longitudinal Caries Development in German Adolescents in the Light of New Caries Measures
}

\author{
Christian H. Splieth Ruth M. Santamaria Roger Basner Elisabeth Schüler \\ Julian Schmoeckel \\ Department of Preventive and Pediatric Dentistry, University of Greifswald, Greifswald, Germany
}

\section{Keywords}

Adolescents, 12-year-olds · Caries prevalence · Germany · National survey

\begin{abstract}
This study assessed the 40-year longitudinal caries development in German adolescents in the light of the sixth National Oral Health Survey in Children (NOHSC, 2016) employing initial DMFT (IDMFT), Significant Caries Index (SiC) and Specific Affected Caries Index ( $\mathrm{SaC}$ ). On the basis of the current NOHSC (randomized cluster selection using school list or regional community school surveys, 55,956 12-year-old sixthgraders examined by 482 calibrated community/study dentists) DMFT, SiC, a novel IDMFT including initial lesions (IT) and the recently introduced $\mathrm{SaC}$ were calculated and also recalculated for national and international surveys from the last 4 decades. In 2016, 78.8\% of children were caries-free (DMFT = 0), 65.5\% including IT lesions. The mean DMFT was 0.44 (single components: $\mathrm{DT}=0.14, \mathrm{MT}=0.02, \mathrm{FT}=0.29, \mathrm{IT}=$ 0.52 ) showing a clear association with the school type as marker for the socio-economic status. The mean number of affected teeth in children with DMFT >0 was $2.07(\mathrm{SaC})$ in comparison to almost 9 teeth in the 1970s. The current care index on the tooth level was $66.3 \%$, leaving only $7.7 \%$ of chil-
\end{abstract}

\section{KARGER}

(c) 2019 S. Karger AG, Basel

E-Mail karger@karger.com

www.karger.com/cre dren with restorative treatment needs. Longitudinally, a continuous caries decline of more than $80 \%$, including the risk groups $(\mathrm{SiC} / \mathrm{SaC})$, to an internationally extremely low level was observed. In conclusion, the National Oral Health Surveys reveal a continuous caries decline to a very low caries level in 12-year-old 6th-graders in Germany even if IT lesions are included (IDMFT). In spite of proportional reductions in the risk groups $(\mathrm{SiC} / \mathrm{SaC})$, the polarized caries distribution according to socio-economic parameters reveals the need for targeted preventive programmes.

(c) 2019 S. Karger AG, Basel

Although caries is not a life-threatening and a preventable disease, its global burden is relevant due to the high prevalence from childhood on and the considerable lifetime costs of this chronic disease [Kassebaum et al., 2015]. Preventive approaches and their monitoring require a solid epidemiological basis, e.g. via regular national representative surveys which have been undertaken in several countries. For the WHO reference group of 12-year-olds, a secular caries decline could be observed for manyindustrialized countries [WHO, 2016]. In Germany, 12-year-olds have been examined in subsequent surveys since 1994/1995 by the German Association for Dental Prevention in Children and Adolescents (DAJ) [Pieper et al., 2013]. 
The aim of this paper is to present the results of the most recent National Oral Health Survey for 12-year-old children in Germany and to analyse the longitudinal caries development in this age group with the former DAJ surveys, other national German surveys [Pieper et al., 2013; IDZ, 2016] and the original WHO surveys from 1973 on [Arnljot et al., 1985; Splieth et al., 1996], which is the basis for a comparison with the caries development in 12 -year-olds in other countries. Due to the caries decline and changes in distribution patterns, additional epidemiological indices, such as the IDMFT which includes initial caries lesions, the Significant Caries Index $(\mathrm{SiC})$ and the newly introduced Specific Affected Caries Index $(\mathrm{SaC})$ [Schmoeckel et al., 2019] were employed and recalculated from the original data of surveys from the last 4 decades.

\section{Materials and Methods}

The German Association for Dental Prevention in Children and Adolescents (DAJ) is the national representation of 17 regional associations (LAGs) being responsible for the implementation of group prevention in kindergarten and school as well as to perform accompanying epidemiological surveys. Mostly community dentists and preventive dental assistants provide these services, and they are mostly obliged to perform regular epidemiological surveys to monitor the success of these programmes. Only in a few federal states, private dentists or special teams fulfil these services. This scheme has resulted in five subsequent surveys from 1994/95 to 2009 and this new survey from 2016 [Team DAJ, 2017] which had been approved by the Ethics Committee at the University of Greifswald (BB48/10a).

\section{Sampling}

For the survey of 2016, the LAGs could opt for either submitting their regular community data seeking at a full survey ( $4 / 17$ regions) or for examining a representative sample, which was drawn by the DAJ and the GESIS Leibniz Institute for the Social Sciences (Mannheim/Germany) via a randomized cluster selection from the official 2014 school lists of middle schools (13/17 regions).

For an overall representative sample, Germany was divided into 17 layers which were identical to the regional bodies. In each layer all relevant school forms with 6th-graders were selected as the clusters. All 12-year-olds in 6th grade in the selected clusters had to be examined. In each layer the number of schools, necessary to be examined, was calculated with data of the last DAJ survey in 2009 [Pieper et al., 2013] and formula based on the total number of 6th-graders, their caries distribution and the probability of error (see online annex; for all online suppl. material, see www.karger. com/doi/10.1159/000501263):

The expected drop-out rate had been set individually between 5 and $30 \%$ depending on the actual response in each of the German regions in the previous survey in 2009 (suppl. Table 1, online annex). After the examination the average DMFT value in the different layers/LAGs opting for the randomized cluster selection could be calculated (see online annex). In each region opting for a full survey, the mean DMFT value was calculated by dividing the sum of DMFT values of all 12-year-olds in 6th grade $T_{h}$ by the number of examined 12-year-olds in 6th grade $M_{h}$.

The balanced mean DMFT value of 12 -year-olds in 6 th grade for Germany could be calculated as sum of the mean DMFT value of each layer multiplied with the calculated coefficient for the layer (suppl. Table 1, online annex). The uneven proportion of 12-yearolds in 6th grade in the different regions is considered by this step.

\section{Realization of the Sampling}

The balanced mean DMFT value of 12-year-olds in 6th grade for Germany could be calculated as sum of the mean DMFT value of each layer multiplied with the calculated coefficient for the layer (suppl. Table 1, online annex). The uneven proportion of 12-yearolds in 6th grade in the different regions is considered by this step.

Many LAGs that had opted for a sampling procedure such as Bavaria, Bremen, Hamburg, Mecklenburg-Pomerania, RhinelandPfalz and Saxonia had no difficulties in fulfilling the required sample or even overrecruiting which led to a secure level of confidence (suppl. Fig. 1, online annex). Also all LAGs that had chosen to perform a full survey examined at least $70 \%$ of all schools, which was estimated as fulfilling the level of confidence [Stang and Jöckel, 2004; Stang et al., 2005]. Very few regions marginally missed to collect the required sample. To verify the data of the LAGs missing the planned sample size, the influence on the level of confidence was checked according to the calculation during the sampling. A maximum of $e=0.27$ could be calculated, and the ranking of the different LAGs/regions should be avoided due to the small range of DMFT values in the regions, but the influence on the overall mean DMFT value for Germany due to these LAGs is less than four thousandths.

\section{Clinical Examination and Calibration}

The examinations were performed at the schools and followed the new consensus guidelines for Standardized Reporting of Oral Health Data in German Community Services [BZÖG, 2013]. The standard WHO [1997] index (DMFT) for teeth with experience of dental caries (caries: DT, missing: MT and filled teeth: FT) was the threshold for recording the presence of decay. In addition, and for the first time in the German Oral Health Survey in Children, the assessment of initial carious lesions (IT) was included. Data were collected by trained and calibrated examiners who were generally employed by community dental preventive services or, where not present, recruited only for the study.

Calibration of examiners was performed using an online platform designed for this purpose. The e-learning system comprised theoretical learning sessions, practical exercises using clinical pictures and a calibration module. Both training and calibration sections could be repeated by the examiners as required.

A total of 482 dentists were calibrated. For all examiners, the interexaminer weighted kappa rank values were calculated [Cohen, 2006]. All interexaminer weighted kappa rank values were $>0.65$, with $44 \%$ of the examiners reaching a substantial agreement $(\kappa=$ $0.65-0.80$ ), and the remaining $56 \%$ an (almost) perfect agreement $(\kappa=0.81-1.00)$.

\section{Statistical Analyses and Data Recording}

Data recording was mostly performed digitally via the existing software at the community services (ISGA, Gudental, Micropro, Octoware/easy-soft) and then transferred to the regional LAG for combining all data into one data sheet in Microsoft Excel ${ }^{\circledR}$, with anonymous recording of the school type, class level, gender, date 
Table 1. Proportion of "caries-free" 12-year-old 6th graders $(\mathrm{DMFT}=0)$ in Germany and its federal states from 1994/1995 to 2016 and without initial caries lesion, carious defects, fillings or missing teeth due to caries for 2016 $(\mathrm{IDMFT}=0)$

\begin{tabular}{|c|c|c|c|c|c|c|c|}
\hline \multirow[t]{2}{*}{ German state } & \multicolumn{6}{|c|}{ "Caries-free" children in permanent dentition $(\mathrm{DMFT}=0), \%$} & \multirow{2}{*}{$-\frac{\mathrm{IDMFT}}{2016}=0$} \\
\hline & $1994 / 95$ & 1997 & 2000 & 2004 & 2009 & 2016 & \\
\hline Baden-Wuerttemberg & 31.7 & 50.2 & 60.0 & 68.6 & 72.2 & 82.3 & 50.1 \\
\hline Bavaria & - & - & - & 54.8 & 62.3 & 71.7 & 55.1 \\
\hline Berlin & 27.0 & 35.6 & 54.8 & 60.0 & 63.6 & 66.4 & 55.6 \\
\hline Brandenburg & - & 33.5 & 52.3 & 54.2 & 64.9 & 76.9 & 70.4 \\
\hline Bremen & 40.0 & - & 49.9 & 59.5 & 62.5 & 66.3 & 53.7 \\
\hline Hamburg & 37.6 & 39.2 & 50.8 & 61.4 & 69.9 & 80.7 & 62.5 \\
\hline Hessen & 32.0 & 44.2 & 59.1 & 62.4 & 73.4 & 81.6 & 71.6 \\
\hline Mecklenburg-Western Pomerania & 15.3 & 24.4 & 38 & 50.9 & 60.4 & 75.8 & 67.6 \\
\hline Lower Saxony & - & - & 55.0 & 63.2 & 72.2 & 78.3 & 66.4 \\
\hline North Rhine-Westphalia & 32.9 & 42.2 & 57.0 & 64.0 & 72.6 & 81.3 & 74.3 \\
\hline Rhineland-Palatinate & 32.1 & 43.2 & 55.9 & 58.1 & 70.0 & 86.6 & 71.1 \\
\hline Saarland & - & - & - & 68.3 & 82.4 & 85.9 & 81.3 \\
\hline Saxony & - & - & - & 59.6 & 71.9 & 79.1 & 73.1 \\
\hline Saxony-Anhalt & 20.6 & 28.3 & 41.8 & 53.8 & 67.4 & 76.7 & 73.0 \\
\hline Schleswig-Holstein & 31.5 & 45.0 & 54.1 & 61.6 & 70.4 & 84.0 & 77.8 \\
\hline Thuringia & 24.6 & 35.0 & 48.2 & 53.3 & 63.5 & 79.2 & 73.0 \\
\hline Westphalia-Lippe & 35.8 & 43.9 & 56.1 & 59.2 & 68.6 & 80.7 & 74.2 \\
\hline Germany (mean) & 30 & 39 & 52 & 60 & 69 & 79 & 68 \\
\hline
\end{tabular}

of birth, examination date and the single components of the DMFT and initial caries lesions (IT) per child.

Caries data were analysed descriptively, regarding prevalence, mean DMFT and its single components (DT, MT, FT) including initial caries lesions (IT). Furthermore, the $\mathrm{SiC}$ as the mean DMFT value of the one third of children with the highest caries levels [Bratthall, 2000] and the recently introduced SaC to identify the risk group in populations with low caries prevalence [Schmoeckel et al., 2019] were calculated and also recalculated for the German epidemiological surveys of the last four decades. For the calculation of the $\mathrm{SaC}$ the following was performed: mean DMFT in the group of individuals with DMFT $>0$ or if caries prevalence and mean DMFT are known: $100 \% /$ (caries prevalence in $\%) \times$ mean DMFT.

For national data the mean values of the federal states were weighted according to their relative size of the population of the age group [Team DAJ, 2017].

\section{Results}

In total, 55,002 12-year-olds in 6th grade were examined in all 17 German regions by the 482 calibrated community or study dentists for the 2016 survey. $78.8 \%$ of these children had not experienced caries on the defect level in their permanent dentition $(\mathrm{DMFT}=0$, Table 1$)$, which was slightly reduced to $65.5 \%$ by including IT lesions.

40-Year Caries Development in German Adolescents
The mean caries prevalence was 0.44 DMFT with almost no permanent teeth missing due to caries with very little variation among the different federal states (Table 2). For the $21.2 \%$ of the children with caries experience on the defect level, the mean DMFT was 2.07, including a mean of 0.65 teeth with carious defects. The $\mathrm{SiC}$ was 1.33 DMFT. The analysis according to the school type and, therefore, socio-economic level revealed a clear association with the caries levels. In the majority of the federal states, 6th-graders are already separated in "Gymnasium" which is intended for preparing an academic carrier, in middle schools for nonacademic jobs or special needs schools. Pupils in "Gymnasium" exhibited about half of the overall mean caries values (0.24 DMFT), while special needs schools with handicapped children or pupils with learning disabilities had about twice the mean value (0.97 DMFT). Thus, a clear risk group of about one fifth of all children can easily be identified in Germany already by school type in 6 th grade.

\section{Treatment Needs}

Only $7.7 \%$ of all these 12 -year-olds exhibited open carious defects and, therefore, a restorative treatment need. In $13.5 \%$ all caries defects had already been treated. At the 
Table 2. Caries experience in 12-year-olds in Germany in the German National Oral Health Survey of 2016: DMFT and subcomponents, Significant Caries Index SiC, mean DMFT in children with caries experience (DMFT $>0, \mathrm{SaC}$ ), care index on tooth level, caries-free children on DMFT level, percentage of children with treatment need DT $>0$, mean DMFT in academic school GYM and special needs schools (SNS)

\begin{tabular}{|c|c|c|c|c|c|c|c|c|c|c|c|c|}
\hline German state & DMFT & IT & DT & $\mathrm{MT}$ & FT & $\mathrm{SiC}$ & $\mathrm{SaC}$ & Care index, \% & $\mathrm{DMFT}=0, \%$ & $\begin{array}{l}\text { Children } \\
\text { with DT } \\
>0, \%\end{array}$ & $\begin{array}{l}\text { DMFT } \\
\text { GYM }\end{array}$ & $\begin{array}{l}\text { DMFT } \\
\text { SNS }\end{array}$ \\
\hline Baden-Wuerttemberg & 0.38 & 1.39 & 0.12 & 0.01 & 0.25 & 1.14 & 2.14 & 69.6 & 82.3 & 6.0 & 0.16 & 0.56 \\
\hline Bavaria & 0.62 & 0.72 & 0.28 & 0.01 & 0.33 & 1.85 & 2.18 & 55.2 & 71.7 & 13.9 & 0.40 & 0.58 \\
\hline Berlin & 0.74 & 0.53 & 0.22 & 0.03 & 0.49 & 2.20 & 2.19 & 70.2 & 66.4 & 13.3 & 0.08 & 1.33 \\
\hline Brandenburg & 0.48 & 0.20 & 0.12 & 0.02 & 0.34 & 1.45 & 2.09 & 76.1 & 76.9 & 6.6 & 0.19 & 1.09 \\
\hline Bremen & 0.65 & 0.58 & 0.23 & 0.02 & 0.40 & 1.95 & 1.94 & 64.8 & 66.3 & 14.5 & 0.30 & 2.75 \\
\hline Hamburg & 0.39 & 0.61 & 0.11 & 0.01 & 0.27 & 1.16 & 2.01 & 72.6 & 80.7 & 6.2 & 0.29 & 0.53 \\
\hline Hessen & 0.38 & 0.38 & 0.09 & 0.02 & 0.27 & 1.13 & 2.06 & 76.4 & 81.6 & 5.2 & 0.21 & 0.56 \\
\hline Mecklenburg-Western Pomerania & 0.46 & 0.31 & 0.07 & 0.02 & 0.38 & 1.38 & 1.89 & 85.6 & 75.8 & 5.2 & 0.40 & 1.02 \\
\hline Lower Saxony & 0.44 & 0.35 & 0.12 & 0.03 & 0.29 & 1.31 & 2.01 & 71.9 & 78.3 & 7.6 & 0.28 & 0.96 \\
\hline North Rhine-Westphalia & 0.38 & 0.23 & 0.09 & 0.02 & 0.28 & 1.14 & 2.03 & 78.7 & 81.3 & 5.2 & 0.24 & 0.96 \\
\hline Rhineland-Palatinate & 0.24 & 0.45 & 0.08 & 0.01 & 0.15 & 0.71 & 1.78 & 65.5 & 86.6 & 5.6 & 0.16 & 0.59 \\
\hline Saarland & 0.27 & 0.11 & 0.08 & 0.02 & 0.17 & 0.81 & 1.91 & 69.8 & 85.9 & 5.4 & 0.19 & 0.26 \\
\hline Saxony & 0.44 & 0.17 & 0.11 & 0.01 & 0.33 & 1.32 & 2.11 & 76.0 & 79.1 & 6.1 & 0.26 & 1.5 \\
\hline Saxony-Anhalt & 0.52 & 0.14 & 0.13 & 0.02 & 0.36 & 1.55 & 2.21 & 75.2 & 76.7 & 7.0 & 0.29 & 1.18 \\
\hline Schleswig-Holstein & 0.33 & 0.19 & 0.06 & 0.01 & 0.26 & 0.99 & 2.07 & 81.8 & 84.0 & 3.7 & 0.17 & 0.44 \\
\hline Thuringia & 0.44 & 0.24 & 0.12 & 0.02 & 0.30 & 1.31 & 2.10 & 72.7 & 79.2 & 7.0 & 0.25 & 1.27 \\
\hline Westphalia-Lippe & 0.40 & 0.23 & 0.11 & 0.01 & 0.27 & 1.19 & 2.06 & 70.2 & 80.7 & 6.7 & 0.27 & 0.97 \\
\hline Germany $^{1}$ & 0.44 & 0.52 & 0.14 & 0.02 & 0.29 & 1.33 & 2.07 & 70.3 & 78.8 & 7.7 & 0.24 & 0.97 \\
\hline
\end{tabular}

${ }^{1}$ Weighted value for Germany according to distribution of population.

tooth level, $66.3 \%$ of the carious teeth had already been filled and 3.9\% had been extracted, while $29.7 \%$ presented with untreated caries.

\section{Longitudinal Development}

The first WHO surveys measured caries prevalence in 13- to 14-year-olds for both parts of Germany (FRG/ GDR), but only in supposedly representative cities (Hannover/West Germany, Leipzig/East Germany) which both high caries prevalence (8.8 and 4.9 DMFT, respectively; Table 3) [Arnljot et al., 1985]. The subsequent surveys in all of West Germany were also performed in 13- to 14-yearolds, but patients who visited dentists within the National Health System (A5/A10) [Dünninger et al., 1995]. These first continuous surveys recorded the first caries decline in 13- to 14-year-olds from 8.8 DMFT in 1983 to 6.4 DMFT in 1989 in (West) Germany. The IDZ studies during German unification showed further reductions to 5.1 DMFT (1989) for West Germany and 4.3 DMFT in East Germany (1992). The DAJ surveys starting in 1994/95 used the new WHO reference group of 12-year-olds, and they also employed representative cohorts of schoolchildren mostly being examined by the community dental services after a calibration. They show an additional marked caries decline for 12-year-olds in 6th grade from 2.44 in 1994/1995 to the current 0.44 DMFT. The values are in excellent agreement with the fewer IDZ surveys which drew representative samples for 12-year-olds from the population records and examined them with very few calibrated study dentists. The 2004-2006 data with both 0.7 DMFT and the 2014-2016 data of 0.5 and 0.44 DMFT for the IDZ and the DAJ survey, respectively, clearly present a further and marked caries decline in spite of the two different recruiting and examination schemes. Within the DAJ studies a caries decline of $82 \%$ can be seen, while adjusting the initial 8.8 DMFT of the WHO and A5 studies for 13- to 14-year-olds to recalculated 6.6 DMFT in 12 -year-olds, the caries decline in West Germany has reduced the initial caries levels by $93 \%$.

The marked decrease in caries levels persists, even with the inclusion of IT lesions (Table 3) which were recorded in 1997 for the first time and have continuously dropped since then. Also, the $\mathrm{SiC}$ comprising the caries levels in a third of the children with the highest caries levels decreased by over $90 \%$. Only the $\mathrm{SaC}$, which calculates the mean caries experience of children with DMFT scores $>0$, was reduced to a slightly lesser extent of $77 \%$ from 1983 to 2016 . 
Table 3. Caries prevalence in adolescents (DMFT, subcomponents, Significant Caries Index ( $\left.\mathrm{SiC}_{\mathrm{DMFT}}\right)$, initial caries lesions IT and mean number of DMFT in children with DMFT (SaC) according to oral health surveys in Germany: initial WHO surveys in 13- to 14-year-olds for Hannover/FRG and Leipzig/GDR, surveys in private practice in all Germany (A5-A10 studies), population register-based surveys by the Institute of German Dentists [IDZ, 2016] and school-based National Oral Health Survey in 12-year-olds in 6th grade by the German Association for Dental Prevention in Children and Adolescents [Team DAJ, 2017]

\begin{tabular}{|c|c|c|c|c|c|c|c|c|}
\hline Study & DMFT & DT & MT & FT & IT & $\mathrm{SiC}_{\mathrm{DMFT}}$ & $\mathrm{DMFT}=0, \%$ & $\mathrm{SaC}_{\text {DMFT }}$ \\
\hline 1973 ICS 1 Hannover region ${ }^{1}$ & 8.8 & 4.4 & 0.4 & 4.1 & & & 1 & $8.9^{7}$ \\
\hline 1979 ICS 1 Leipzig region ${ }^{1}$ & 4.9 & 1.6 & 0.2 & 3.0 & & & 10 & $5.4^{7}$ \\
\hline 1983 A5 West Germany ${ }^{2}$ & 8.8 & 2.8 & $0.3^{5}$ & 5.7 & & & 2 & $9.0^{7}$ \\
\hline 1989 IDZ West Germany ${ }^{3}$ & 5.1 & 2.1 & 0.1 & 3.0 & & $9.6^{6}$ & 13 & $5.9^{7}$ \\
\hline 1989 A10 West Germany ${ }^{2}$ & 6.4 & 3.2 & 0.2 & & & & 11 & $7.2^{7}$ \\
\hline 1992 IDZ East Germany ${ }^{3}$ & 4.3 & 0.7 & 0.1 & 3.5 & & $8.4^{6}$ & 16 & $5.1^{7}$ \\
\hline $1994 / 94 \mathrm{DAJ}^{4}$ & 2.44 & 0.43 & 0.05 & 1.98 & & 5.33 & 30 & $3.5^{7}$ \\
\hline $1997 \mathrm{DAJ}^{4}$ & 1.75 & 0.33 & 0.03 & 1.44 & & 4.46 & 39 & $2.8^{7}$ \\
\hline $1997 \mathrm{IDZ}^{4}$ & 1.7 & 0.4 & 0.0 & 1.3 & 3.0 & 4.1 & 42 & $2.9^{7}$ \\
\hline $2000 \mathrm{DAJ}^{4}$ & 1.21 & 0.23 & 0.03 & 0.98 & & 3.43 & 52 & $2.5^{7}$ \\
\hline $2004 \mathrm{DAJ}^{4}$ & 0.98 & 0.24 & 0.03 & 0.68 & & 2.99 & 60 & $2.5^{7}$ \\
\hline 2004 IDZ $^{4}$ & 0.7 & 0.7 & 0.2 & 0.5 & 0.9 & 2.1 & 70 & $2.3^{7}$ \\
\hline $2009 \mathrm{DAJ}^{4}$ & 0.72 & 0.22 & 0.02 & 0.48 & & 2.18 & 69 & $2.3^{7}$ \\
\hline $2014 \mathrm{IDZ}^{4}$ & 0.5 & 0.1 & 0.1 & 0.3 & 0.6 & 1.4 & 81 & $2.6^{7}$ \\
\hline $2016 \mathrm{DAJ}^{4}$ & 0.44 & 0.14 & 0.02 & 0.29 & 0.52 & 1.33 & 79 & 2.1 \\
\hline
\end{tabular}

$\mathrm{SaC}_{\mathrm{DMFT}}$, mean DMFT in the group with DMFT $>0 .{ }^{1} \mathrm{WHO}, 13$ - to 14-year-olds, mean value between metropolitan and non-metropolitan area [Arnljot et al., 1985]. ${ }^{2}$ A studies, 13- to 14-year-olds in dental practices [Dünninger et al., 1995]. ${ }^{3}$ IDZ, 13 - to 14 -year-olds, representative sample [IDZ, 2016]. ${ }^{4}$ DAJ and IDZ studies, 12-year-olds, representative samples, DAJ recorded in 6th grade [TEAM DAJ, 2017; IDZ, 2016]. ${ }^{5}$ Original figure was 2.3 MT with inclusion of premolar extractions due to orthodontics, recalculated by study later to $0.3 \mathrm{MT}$. ${ }^{6}$ Calculated from distribution of original data. ${ }^{7}$ Calculated from original data by: 100/(caries prevalence).

\section{Discussion}

Until German unification in 1990, epidemiological studies found relatively high caries values for adolescents which is outlined in the results section of this paper. A comparative study on children's dental health in Europe among eight EU countries found the highest DMFT values in the 12-year-olds in Germany, Greece and Italy [Bolin, 1997].

The high caries levels and the starting caries decline in Switzerland or Nordic countries sparked in the 1980s a discussion in the Federal Republic of Germany (West) and the East German Democratic Republic to introduce structured group prevention and individualized prevention in the national health system by law and compulsory epidemiological surveys in West Germany [IDZ, 2016, Team DAJ, 2017]. The East German system concentrated on water fluoridation, fluoride tablet use in kindergarten and schools, but fluoridated toothpaste was hardly used [Splieth and Meyer, 1996]. With unification, East Germany joined the West German system which gives an excellent structural frame to deliver caries prevention to children and adolescents at many levels and monitor the outcome regularly which is justified by the high disease burden and costs which are created by caries.

Thus, a very consistent set of surveys and data on caries prevalence in adolescents exists in Germany, and it reveals an impressive caries decline of more than $90 \%$ in 45 years. In spite of some variation in methods used to determine national mean DMFT scores in adolescents in Germany and Europe over time [Patel et al., 2016], the DMFT seems to be an extremely robust instrument to monitor caries experience, and the longitudinal caries development is quite clear in spite of varying set-ups. This is especially true for Germany where the IDZ and DAJ studies implemented extremely different recruiting strategies for participants and examining dentists, but the results at each point of time are almost identical [IDZ, 2016; Team DAJ, 2017].

The inclusion of IT lesions (IDMFT) or the use of subanalyses for the caries risk group ( $\mathrm{SiC}, \mathrm{SaC}$ ) allow a more 
detailed description of the caries patterns, but they exhibit a similar caries decline as the DMFT. Still, for the public health perspective it is of prime interest how evenly the caries reductions are distributed and how successful the caries-preventive strategies are for the high-risk groups.

\section{International Comparison}

In contrast to the comparatively high caries levels in Germany in the 1980s, the current caries prevalence is now one of the lowest (Table 4 ). About $80 \%$ of the 12 -yearolds are caries-free at the cavity level $(\mathrm{DMFT}=0)$, which was extremely rare in the 1970s and 1980s [Arnljot et al., 1985]. Even the inclusion of IT lesions does not change the picture considerably, and the trend is uniform for the different federal states in Germany.

Similar trends in caries prevalence have been reported in other countries, e.g. in Portugal, Slovenia or Korea, but the most recent caries levels are about twice to 4 times the current German values (1.18, 1.9 and 1.8, respectively) in spite of high sealant rates (Portugal: 55\% of 12 -year-olds, mean 3.61; Slovenia 92\%) [Calado et al., 2017; Kim et al., 2017; Vrbič and Vrbič, 2016].

\section{Potential Reasons for the Caries Decline}

As the caries decline in the primary dentition in Germany is much less satisfactory than in the permanent dentition, the question arises why the same children, parents, dental teams and national health system result in one of the world's lowest caries levels in the permanent dentition, but not in the primary dentition [Team DAJ, 2017]. According to the available evidence, fluorides are the key point for the caries decline, especially fluoridated toothpaste [Bratthall, 2000; Walsh et al., 2010]. West Germany has been widely using fluoridated toothpaste in the 1980s, where the first caries decline was detected in 8- to 9-year-olds. East Germany had problems with manufacturing fluoridated toothpaste [Splieth and Meyer, 1996] which led to a minimal use, and in spite of many other measures in caries prevention such as water fluoridation or the use of fluoride tablets in kindergarten and schools, no national caries decline could be observed before unification [Künzel, 1988]. In contrast to about $1,500 \mathrm{ppm}$ fluoride in the toothpaste from 6 years on, paediatric toothpaste only contains $500 \mathrm{ppm}$ which could explain the lesser decline in the primary dentition. This is supported by an English analysis which concluded that the reduction in caries levels among 5-year-olds has most likely been brought about by the wider availability of children's toothpaste of at least 1,000 ppm fluoride [Davies et
Table 4. International comparison of mean caries experience (DMFT) in 12-year-olds [WHO, 2016]

\begin{tabular}{|c|c|c|}
\hline Country & Year & DMFT \\
\hline Denmark & 2014 & 0.4 \\
\hline Germany $(\mathrm{DAJ})^{1}$ & 2016 & 0.4 \\
\hline Germany (IDZ) & 2014 & 0.5 \\
\hline Finland & 2009 & 0.7 \\
\hline UK & 2007-2008 & 0.7 \\
\hline Sweden & 2011 & 0.8 \\
\hline Belgium & 2009-2010 & 0.9 \\
\hline Switzerland $^{2}$ & 2011 & 0.9 \\
\hline France & 2006 & 1.2 \\
\hline Portugal & 2013-2014 & 1.2 \\
\hline USA & 1999-2004 & 1.2 \\
\hline Italy $^{3}$ & 2012 & 1.2 \\
\hline Austria & 2007 & 1.4 \\
\hline Norway & 2004 & 1.7 \\
\hline Turkey & 2004-2005 & 1.9 \\
\hline Belarus & 2009 & 2.1 \\
\hline Hungary & 2008 & 2.4 \\
\hline Czechia & 2006 & 2.6 \\
\hline Poland & 2014 & 2.8 \\
\hline Russian Federation $^{4}$ & 2007-2008 & 2.9 \\
\hline Albania & 2011 & 3.7 \\
\hline Croatia & 2013-2015 & 4.2 \\
\hline
\end{tabular}

${ }^{1} 12$-year-olds in 6 th grade. ${ }^{2}$ Canton Basel-Land. ${ }^{3}$ Campania. ${ }^{4}$ North-west Russia.

al., 2017], while the levels of gingivitis which are related to plaque and plaque removal were almost stable over 40 years [Murray et al., 2015].

The other most important factor in the exceptionally high caries reductions in German adolescents could be the nation-wide combined and well-structured implementation of group and individualized prevention in 1989. By law, group prevention in schools has to be organized and financed by the insurances of the national health system. It is organized with the regional community dental services and private practitioners. The individualized prophylaxis in the private practices within the national health system includes the semi-annual assessment of the oral hygiene status, brushing instruction, topical fluoride application and sealants for permanent molars, while the visits are only annually before the 6th birthday and group prevention below the age of 3 years is rare. Thus, the German caries-preventive measures are well structured, established and widely used [KZBV, 2018], but clearly concentrated on the permanent dentition which could be the reason for caries decline there and the much lesser extent in the primary dentition. 
Sealants are often regarded as a key stone in caries prevention, especially in children where pits and fissures are overproportionally affected [Wright et al., 2016]. The sealant rate in 12-year-olds in Germany of 70\% [IDZ, 2016] was comparatively lower than in Slovenia (92\%), or the mean number of sealants with 2.8 was lower than in Portugal (3.6), but the mean caries experience in Germany is only one fourth of the Slovenian or the Portuguese. In Denmark, the community with the lowest caries rates (Nexö) also had very low sealant rates [Ekstrand et al., 2007]. Thus, it seems to be feasible to achieve very low caries levels with a minimal use of sealants, and the main driver of the caries decline (in Germany) could be a reduction of caries activity by the regular applications of fluorides in combination with plaque removal, meaning tooth brushing.

In conclusion, the comparatively high caries levels in German adolescents of the 1970s and 1980 could be reduced by over $90 \%$ to internationally very low caries values. The combined, nation-wide group and individualized preventive programmes as well as the accompanying epidemiological survey offer an excellent structure for the implementation of caries-preventive measures and the monitoring of the outcome.

The only remaining challenge is the disparities in oral health: after a general decline, caries is almost exclusively restricted to a minority associated with low socio-economic state or even deprivation. This can be observed in many countries [Vernazza et al., 2016], and it requires relevant consequences in clinical and public dental prevention.

\section{Acknowledgements}

The authors want to thank the Deutsche Arbeitsgemeinschaft für Jugendzahnpflege e.V. (DAJ) for the excellent cooperation in the National Oral Health Survey 2016 and for generating the DAJ report 2017.

\section{Disclosure Statement}

The authors declare no conflict of interest.

\section{References}

Arnljot HA, Barmes DE, Cohen LK, Hunter PB, Ship II. Oral health care systems: an international collaborative study coordinated by the World Health Organization. Geneva: World Health Organization; 1985.

Bolin AK. Children's dental health in Europe. An epidemiological investigation of 5- and 12-year-old children from eight EU countries. Swed Dent J Suppl. 1997;122:1-88.

Bratthall D. Introducing the Significant Caries Index together with a proposal for a new global oral health goal for 12-year-olds. Int Dent J. 2000 Dec;50(6):378-84.

BZÖG (Bundesverband der Zahnärzte im Offentlichen Gesundheitsdienst). Empfehlungen zur standardisierten Gesundheitsberichterstattung für die zahnärztlichen Dienste im öffentlichen Gesundheitsdienst. Berichte und Materialien. Vol 25. Düsseldorf: Akademie für Öffentliches Gesundheitswesen; 2013.

Calado R, Ferreira CS, Nogueira P, Melo P. Caries prevalence and treatment needs in young people in Portugal: the third national study. Community Dent Health. 2017 Jun;34(2): 107-11.

Cohen J. A coefficient of agreement for nominal scales. Educ Psychol Meas. 2006;20(1):37-46.

Davies GM, Neville J, Jones K, White S. Why are caries levels reducing in five-year-olds in England? Br Dent J. 2017 Nov;223(7):515-9.

Dünninger $\mathrm{P}$, Uhl T, Einwag J, Naujoks R. Die Veränderung der Mundgesundheit in der Bundesrepublik Deutschland - das
Projekt A10. Dtsch Zahnärztl Z. 1995;50: 40-4.

Ekstrand KR, Martignon S, Christiansen ME. Frequency and distribution patterns of sealants among 15-year-olds in Denmark in 2003. Community Dent Health. 2007 Mar;24(1): 26-30.

IDZ (Institut der Deutschen Zahnärzte). Fünfte Deutsche Mundgesundheitsstudie - DMS V. Köln: IDZ; 2016.

Kassebaum NJ, Bernabé E, Dahiya M, Bhandari B, Murray CJ, Marcenes W. Global burden of untreated caries: a systematic review and metaregression. J Dent Res. 2015 May;94(5): 650-8.

Kim AH, Shim YS, Kim JB, An SY. Caries Prevalence in Korean Children and Adolescents from 2000 to 2012. J Clin Pediatr Dent. 2017; 41(1):32-7.

Künzel W. Allgemeiner Kariesrückgang in der jugendlichen Population der DDR? Zahn Mund Kieferheilkd. 1988;76:559-65.

KZBV (Kassenzahnärztliche Bundesvereinigung). Jahrbuch 2017. Berlin: KZBV; 2018.

Murray JJ, Vernazza CR, Holmes RD. Forty years of national surveys: an overview of children's dental health from 1973-2013. Br Dent J. 2015 Sep;219(6):281-5.

Patel RN, Eaton KA, Pitts NB, Schulte A, Pieper K, White S. Variation in methods used to determine national mean DMFT scores for 12-yearold children in European countries. Community Dent Health. 2016 Dec;33(4):286-91.
Pieper K, Lange J, Jablonski-Momeni A, Schulte AG. Caries prevalence in 12-year-old children from Germany: results of the 2009 national survey. Community Dent Health. 2013 Sep; 30(3):138-42.

Schmoeckel J, Santamaria RM, Basner R, Schüler $\mathrm{E}$, Splieth $\mathrm{CH}$. Introducing a specific term to present caries experience in populations with low caries prevalence - SaC. Caries Res. 2019 Mar;1-5. Epub ahead of print.

Splieth C, Meyer G. Factors for changes of caries prevalence among adolescents in Germany. Eur J Oral Sci. 1996 Aug;104(4 (Pt 2)):444-51.

Stang A, Jöckel KH. Studies with low response proportions may be less biased than studies with high response proportions. Am J Epidemiol. 2004 Jan;159(2):204-10.

Stang A, Moebus S, Dragano N, Beck EM, Möhlenkamp S, Schmermund A, et al.; Heinz Nixdorf Recall Study Investigation Group. Baseline recruitment and analyses of nonresponse of the Heinz Nixdorf Recall Study: identifiability of phone numbers as the major determinant of response. Eur J Epidemiol. 2005;20(6):489-96.

Team DAJ. Epidemiologische Begleituntersuchungen zur Gruppenprophylaxe 2016. Bonn DAJ; 2017.

Vernazza CR, Rolland SL, Chadwick B, Pitts N. Caries experience, the caries burden and associated factors in children in England, Wales and Northern Ireland 2013. Br Dent J. 2016 Sep;221(6):315-20. 
Vrbič V, Vrbič M. Epidemiology of Caries in 12-Year-Olds in Slovenia 1987-2013. Oral Health Prev Dent. 2016;14(5):467-73.

Walsh T, Worthington HV, Glenny AM, Appelbe P, Marinho VC, Shi X. Fluoride toothpastes of different concentrations for preventing dental caries in children and adolescents. Cochrane Database Syst Rev. 2010 Jan;1:CD007868.
WHO (World Health Organization). Oral health database. 2016. Available from: http://www. MAH.SE.CAPP/

WHO (World Health Organization). Oral health surveys: basic methods. 4th ed. Geneva: WHO; 1997.
Wright JT, Crall JJ, Fontana M, Gillette EJ, Nový BB, Dhar V, et al. Evidence-based clinical practice guideline for the use of pitand-fissure sealants: A report of the American Dental Association and the American Academy of Pediatric Dentistry. J Am Dent Assoc. 2016 Aug;147(8):672-682. e12. 